\title{
Biorefinery approach applied to the valorization of purple
}

\section{corn cob}

Patrizia De Nisi, Giulia Borlini, Parisa Abbasi Parizad, Alessio Scarafoni, Piero Sandroni, Elena Cassani, Fabrizio Adani* and Roberto Pilu*

\section{AUTHOR INFORMATION}

*corresponding authors

Fabrizio Adani - Department of Agricultural and Environmental Sciences, Production, Landscape and Agroenergy (DiSAA), Gruppo Ricicla, Università degli Studi di Milano, via Celoria 2, Milan, I-20133, Italy. Email: fabrizio.adani@unimi.it

Roberto Pilu - Department of Agricultural and Environmental Sciences, Production, Landscape and Agroenergy (DiSAA), Agriculture Genetic Group, Università degli Studi di Milano, via Celoria 2, Milan, I-20133, Italy. Email: salvatore.pilu@unimi.it

\section{Authors}

Patrizia De Nisi - Department of Agricultural and Environmental Sciences, Production, Landscape and Agroenergy (DiSAA), Gruppo Ricicla, Università degli Studi di Milano, via Celoria 2, Milan, I-20133, Italy. Email: patrizia.denisi@unimi.it

Giulia Borlini - Department of Agricultural and Environmental Sciences, Production, Landscape and Agroenergy (DiSAA), Agriculture Genetic Group, Università degli Studi di Milano, via Celoria 2, Milan, I-20133, Italy. Email: giulia.borlini@unimi.it 
Parisa Abbasi Parizad - Department of Agricultural and Environmental Sciences, Production, Landscape and Agroenergy (DiSAA), Gruppo Ricicla, Università degli Studi di Milano, via Celoria 2, Milan, I-20133, Italy. E-mail: parisa.abbasi@unimi.it

Alessio Scarafoni - Department of Food, Environmental and Nutritional Sciences (DeFENS), Università degli Studi di Milano, via Celoria 2, Milan, I-20133, Italy. Email:

alessio.scarafoni@unimi.it

Piero Sandroni - C. Sandroni \& C. Srl, via Caboto 2, Busto Arsizio, I-21052, Italy. Email: piero@sandroni.it

Elena Cassani - Department of Agricultural and Environmental Sciences, Production, Landscape and Agroenergy (DiSAA), Agriculture Genetic Group, Università degli Studi di Milano, via Celoria 2, Milan, I-20133, Italy. Email: elena.cassani@unimi.it 


\section{- ABSTRACT}

The increased demand for textile products and the use of synthetic dyes have contributed to making dye wastewater one of the main causes of severe pollution problems. The use of natural dyes is therefore attracting big interest among the dyeing industries. Besides this, natural pigments need to be low-cost, with implications for the extraction methods used. Recovering pigments from waste materials and proposing a biorefinery approach can be a solution, reducing total costs and increasing total revenue, within the green economy.

This work reports a biorefinery approach to recover anthocyanins by set up a quick and cheap extraction method, starting from dried purple corn cob, to obtain pigments used to dye natural fibres. The residues of the cobs were extracted, recovering anthocyanins for nutraceutical purposes. The exhausted residue was proposed as animal bedding, closing the loop with zero waste produced, i.e. residual animal bedding is collected with food waste producing compost and/or biogas, and fertilizers. Water extraction allowed the recovery of $36.3 \%$ of anthocyanins, mainly composed of cyanidin derivatives (glycosylated and mainly monoacylated). The use of the first extract to dye fabrics gave good results in terms of colour strength and fastness. The subsequent extraction with ethanol allowed the recovery of additional $33.2 \%$ of residual anthocyanins. The anthocyanin-rich extract exhibited very good anti-inflammatory activity with high nutraceutical potential. Residual exhausted ground-up cobs are recommended to be used as animal bedding since fiber content and water retention ability were very similar to that of homologous commercial

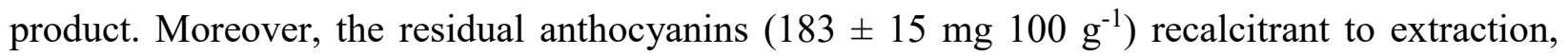
conferred interesting properties to the proposed animal bedding. 


\section{- KEYWORDS}

Purple corn cob; Circular economy; Green chemistry; Anthocyanins extract; Natural dyeing; Bioactive compounds; Anti-inflammatory activity; Animal bedding.

\section{- Introduction}

Textile industries, throughout the globe, produce and use approximately 1.3 million $\mathrm{Mg}$ of dyes, pigments, and dye precursors that cost around $\$ 23$ billion each year. ${ }^{1}$ Thus, textile industries generate toxic and hazardous chemical wastes which cause a threat to human health and the environment. For these reasons, the use of natural dyes is attracting more and more interest among the dyeing industries. ${ }^{2}$ Since antiquity, natural dyes have been used to help to adorn human beings; for instance, in 2,000 BC the Chinese and the Sumerians in Iraq, already utilized indigo in painting and dyeing clothes. ${ }^{1}$

Natural pigment used as dyeing are generally extracted from vegetable substances, fungal species and animals. Among the plant pigments, anthocyanin are the most important pigments of the vascular plants and they are considered to be interesting for their use as natural water-soluble colourants $^{3}$ although natural fibres require dyeing in conjunction with metallic mordant such as $\mathrm{Fe}, \mathrm{Al}, \mathrm{Cu}, \mathrm{Pb}$, and $\mathrm{Sn}^{4,5} \mathrm{In}$ addition anthocyanins are known to be nontoxic, and to act as antioxidant, bioactive components in nutraceutical, ${ }^{6}$ antifungal, antibacterial ${ }^{7}$ and UVprotective. ${ }^{8}$

The isolation of anthocyanin pigments from plants is typically done using solvent extraction processes. Anthocyanins are polar molecules and consequently more soluble in polar solvents: acetone is the most commonly used solvent, but it is also considered more toxic and hazardous, 
needing to be handled with more precautions than ethanol, that, for example, is more environmentally friendly. The best extraction yield is obtained with this solvent, which is however expensive. Recently, in addition to conventional solvent-based anthocyanin extraction methods, other methods including supercritical $\mathrm{CO}_{2},{ }^{9}$ ultrasound and microwave-assisted extraction ${ }^{10}$ have been proposed.

Water is an essential medium for dyeing natural fabrics with natural polar pigments such as anthocyanins. ${ }^{11}$ Nevertheless, using water greatly reduces extraction yields, leaving large amounts of anthocyanins in plant tissues, that in theory could be recovered for other purposes by a cascade approach, i.e., biorefineries, aimed at limiting the waste produced and increasing the numbers of products.

In recent years, in Italy, several farmers have started the production of pigmented maize because different epidemiological and preclinical studies have demonstrated that regular consumption of anthocyanin-rich foods is associated to a reduced risk of chronic diseases, such as cardiovascular diseases, cancer, obesity and diabetes. ${ }^{12-15}$ The most effective anthocyanins appeared to be both cyanidin-3-glucoside (CyG) and pelargonidin-3-glucoside (PlG). ${ }^{14}$ Several varieties of coloured maize rich in different pigments have been studied and developed by classical breeding ${ }^{16-21}$ that could be used as cheap sources of dyes and natural mordants, after their extraction by hydro-alcoholic solution from corn residues, i.e., cobs and corn stover, that need to be valorised.

Earlier investigations indicated that in purple corn, pigments were located at especially high levels in the inedible husk and cob tissue, and it was also found that corn varieties and the extraction methods employed can affect anthocyanins content. 
On average, the seeds that represented $82 \%$ of dry matter of the ear contains about $55 \%$ of total anthocyanins (ranging from 0.2 to $115{\mathrm{mg} 100 \mathrm{~g}^{-1} \text { ) } 22-26}$ being the remaining fraction of anthocyanins, i.e. $45 \%$, in the cob.

Non-food biomass such as corn cob is recalcitrant to biodegradation due to the low water content and owing to the lignocellulosic nature of the materials, organized as the rigid and compact structure of the cell walls. ${ }^{27}$ These features make the purple corn cob an excellent raw material rich in anthocyanins, which remains stable over time, and these molecules are available to be extracted at any time.

This work aimed to recover anthocyanins from purple dried corn cobs by proposing a quick and cheap extraction method to obtain anthocyanin pigments to be used to dye different natural fibres (cotton and wool). In addition, waste streams generated were successively recovered by a cascade approach to produce nutraceutical products and pigmented litter for pets. 


\section{Experimental section}

Corn crop and plant material. A new variety of pigmented F1 hybrid corn

(Zea mays L.) carrying B (Booster 1) and Pl (Purple Plant) regulatory genes, was used as the source of plant material in this study. ${ }^{20}$ Plants were grown in the experimental field (2018 crop year) of the University of Milan located in Landriano (Italy) (N 45180', E $\left.9^{\circ} 150^{\prime}\right)$.

The ears, harvested and dried, were shelled (by electric sheller); kernels were collected separately and preserved. Corn cobs obtained were ground by grinder (electric chipper, Home and Garden 0600853600, $2200 \mathrm{~W}$, Bosch, Robert Bosch $\mathrm{GmbH}$ ), and reduced to particle sizes of 1-3 $\mathrm{mm}$. The dried and milled corn cobs had a moisture content of about $4 \%$ fresh weight.

\section{Anthocyanins extraction and quantification on raw material.}

Conventional extraction. Anthocyanins from corn cob were extracted by using two conventional solvent types: $i$. ethanol 50\% acidified with $0.01 \%$ HCL 6 M and $i i$ acetone solution $70 \%{ }^{28}$ Solvents were mixed with the ground purple cobs (solid-liquid ratio of 1:50 w/v) and stirred at room temperature. After $12 \mathrm{~h}$ stirring at room temperature, the mixture was centrifuged at 3,000 rpm for $10 \mathrm{~min}$, and the resulting clear supernatant was filtered and analyzed for its anthocyanins content.

Total anthocyanins content (TAC). Anthocyanins quantification was spectrophotometrically determined using the $\mathrm{pH}$-differential method. ${ }^{29}$ To the aliquots, properly diluted, of extract were added $3 \mathrm{ml}$ of $0.025 \mathrm{M}$ of potassium chloride buffer $(\mathrm{pH} 1.0)$ and $0.4 \mathrm{M}$ of sodium acetate buffer 
(pH 4.5); after $20 \mathrm{~min}$, absorbance at 520 and $700 \mathrm{~nm}$ was measured. TAC was calculated as CyG equivalent per 100 g sample.

\section{Biorefinery process.}

The raw material was subjected to an anthocyanin's extraction process by two sequential extractions, each one having a different purpose, illustrated in the scheme in Figure1.

Step 1: water soluble anthocyanins extraction for direct dyeing. Extraction was performed by adopting a solid-liquid ratio of 1:10 (w/v), which allowed us to extract an anthocyanins concentration of almost $300 \mathrm{mg} \mathrm{L}^{-1}$, that was indicated as an adequate concentration for dyeing fabric with anthocyanins. ${ }^{30}$ To determine the effects of temperature on anthocyanins recovery some experimental extraction tests were performed at different temperatures, ${ }^{31}$ i.e., $25,50,70,85$ $\& 100{ }^{\circ} \mathrm{C}($ Figure $\mathrm{S} 1)$. 


\section{Raw Material [100]}

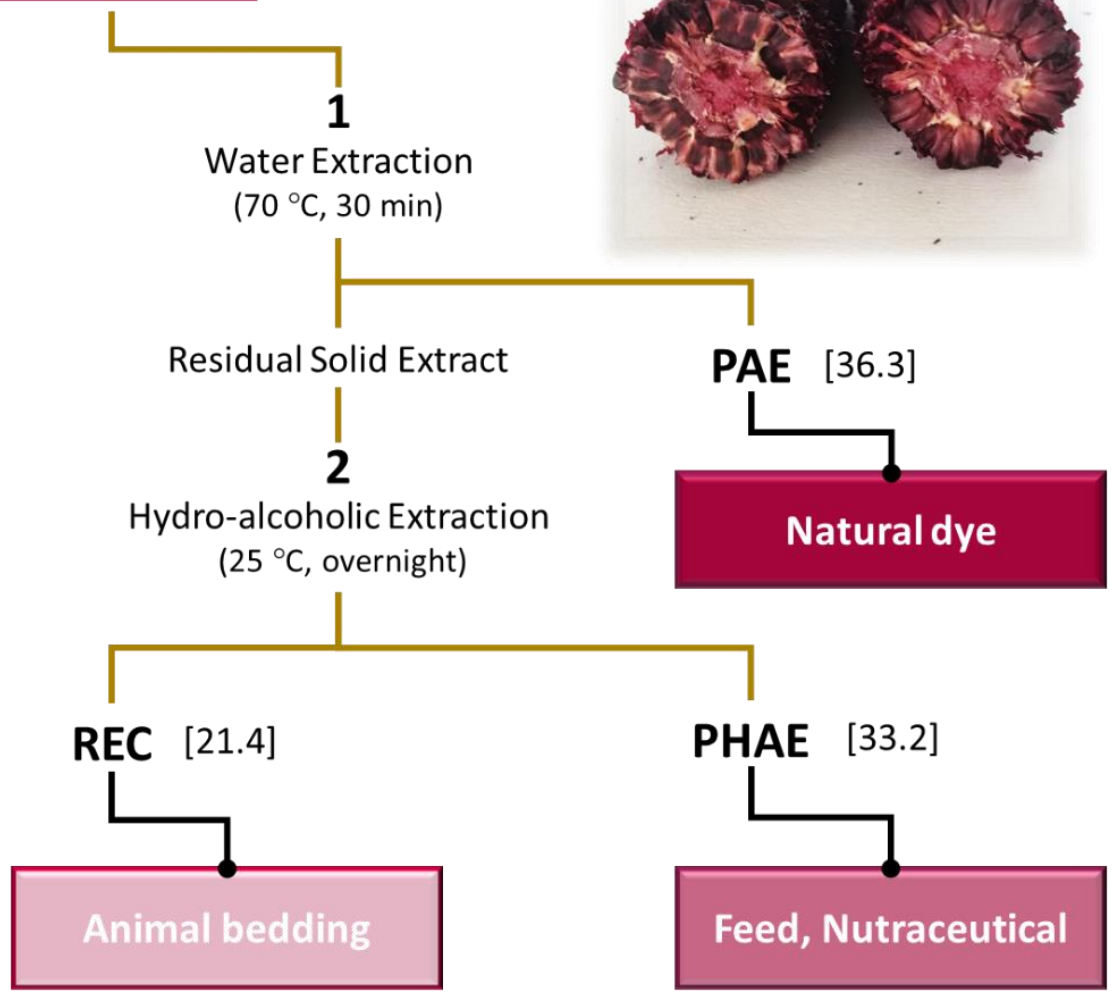

Figure 1. Framework of the biorefinery approach in valorizing purple corn cob. In square brackets, the relative anthocyanins yield expressed in percent of starting content [100] in raw material. Biorefinery products: pigmented aqueous extract (PAE); pigmented hydro alcoholic extract (PHAE); residual exhausted cob (REC).

In the light of these assessments, the first extraction method was done using $100 \mathrm{~g}$ of ground corn cob which were suspended in $1 \mathrm{~L}$ of water at $70^{\circ} \mathrm{C}$ and stirred for $30 \mathrm{~min}$. The suspension was filtered and the pigmented aqueous phase clarified by centrifugation at 3,000 rpm for 10 min; clear supernatant was filtered and analyzed for TAC. The first corn cob extract, named 
pigmented aqueous extract (PAE), was characterized and employed for fabric dyeing tests. The corn cob solid residue was collected separately and subjected to a second extraction.

Step 2: hydroalcoholic anthocyanins extraction for nutraceutical use. Water based solvent is quite effective in the extraction of bioactive molecules from purple corn cob but the remaining solid residues evidently contained other anthocyanins (persistent reddish color still present) that can be recovered by using stronger solvents and/or a second extraction. Therefore, following the first extraction, the resulting cake was treated with hydroalcoholic solvent, i.e., $50 \%$ ethanol slightly acidified with $0.01 \% \mathrm{HCl} 6 \mathrm{M}^{28}$, at room temperature, overnight and under stirring, for a further anthocyanin extraction. Doing so, the solution $\mathrm{pH}$ was below 2, enhancing anthocyanins solubility and stability and total anthocyanins yield, without hydrolyzing their original form. ${ }^{28}$

The suspension was filtered and clarified by filtration with filter paper. The pigmented hydro alcoholic extract (PHAE) was successively characterized in both quantitative and qualitative terms and evaluated for nutraceutical properties, based on antioxidant and anti-inflammatory capacities. The lignocellulosic solid phase was washed for $30 \mathrm{~min}$ with distilled water $(1: 5 \mathrm{w} / \mathrm{v})$, to eliminate the residual acid, collected by filtration and dried at $60{ }^{\circ} \mathrm{C}$ overnight.

\section{Recovery of depleted cobs.}

The dried residual exhausted cob (REC in Figure 1), retained after the anthocyanin extraction process, was subsequently characterized and analyzed to determine its suitability to be used as animal bedding 


\section{Quantification and characterization of phytochemicals in biorefinery}

\section{products.}

Total anthocyanins content $(\boldsymbol{T A C})$. Anthocyanins quantification was spectrophotometrically determined such previously reported for raw material ${ }^{29}$.

Anthocyanin compounds. Anthocyanins identification was performed by a chromatographic analytical approach on both of the different liquid extracts (PAE and PHAE) and the final solid residue $(\mathrm{REC})$.

HPLC-DAD anthocyanins characterization was conducted with LC-20AD Series Shimadzu Prominence liquid chromatograph (Kyoto, Japan). The instrument was equipped with SPDM20A diode-array detector. The chromatographic separation of the pigments was carried out by Luna ${ }^{\circledR}$ Omega C18 column (Torrance, USA) $3 \mu \mathrm{m}, 3.0 \times 150 \mathrm{~mm}$. The mobile phase was composed by aqueous solution of $1 \%(\mathrm{v} / \mathrm{v})$ formic acid (solvent $\mathrm{A}$ ) and $100 \%$ acetonitrile (solvent B); the gradient program was: $10 \% \mathrm{~B}$ for $1 \mathrm{~min}, 15 \% \mathrm{~B}$ at $10 \mathrm{~min}, 20 \% \mathrm{~B}$ at $20 \mathrm{~min}$, $45 \% \mathrm{~B}$ at $40 \mathrm{~min}$, then returning to $10 \% \mathrm{~B}$. Samples were properly diluted in solvent A and analysis was conducted under the following chromatographic conditions: flow rate of $0.4 \mathrm{~mL}$ $\min ^{-1}$, injection volume of $10 \mu \mathrm{L}$ and column temperature of $30^{\circ} \mathrm{C}$. Anthocyanins were detected at $520 \mathrm{~nm}$ and $280 \mathrm{~nm}$ by using a diode-array detector set up for an acquisition in the range 200$600 \mathrm{~nm}$ and an acquisition rate of $1.25 \mathrm{scans} \mathrm{s}^{-1}$ (peak width $0.2 \mathrm{~min}$ ). LabSolution software version 5.90 (Shimadzu Corporation, Kyoto, Japan) was used both to control the HPLC system and for data processing. 
Anthocyanins recognition was confirmed by liquid chromatography coupled with mass spectrometry (LC/MS). Detection was made by the LC/MS system 6130 Series from Agilent Technologies (Agilent Technologies, CA, USA) equipped with an Electro Spray Ionization (ESI) source and liquid chromatography sprayer and operated in the positive-ion mode. Analyses were performed by using both the same chromatographic separation conditions and column above described; injection volume was of $2 \mu \mathrm{L}$. Mass spectra were obtained under positive ion conditions using total ion scan (SCAN) from m/z 100 to 1000 and selected ion monitoring (SIM) modes. The MS settings were optimized for CyG signal-to-noise ratio. The capillary voltage was of $+5.0 \mathrm{kV}$, the nebulizer pressure of $1.7 \mathrm{bar}$, the drying gas flow of $9 \mathrm{~L} \mathrm{~min}^{-1}$ and the drying temperature $350{ }^{\circ} \mathrm{C}$. Compounds were detected as positive ions $\left([\mathrm{M}-\mathrm{H}]^{+}\right)$at different channels: m/z 449 CyG, m/z 535 (cyanidin-3-malonyl glucoside, CyMG), m/z 433 (pelargonidin-3glucoside, PlG), m/z 463 (peonidin-3-glucoside, PnG). For data processing ChemStation software Rev.B.04.03 (Agilent Technologies, CA, USA) was used.

Total Polyphenols (TP). The determination of the TP was carried out directly on diluted aliquots of the PAE and PHAE extracts. For the quantification of total polyphenol contents of REC, $0.5 \mathrm{~g}$ of dried material was weighed, mixed with $20 \mathrm{~mL}$ of $70 \%$ (v/v) aqueous methanol and shaken at room temperature for 6 hours. TP was determined by the Folin-Ciocalteu assay ${ }^{32}$; briefly, to the extracts (PAE, PHAE and REC extracts) properly diluted were added $1 \mathrm{~mL}$ of Folin-Ciocalteau reagent. The mixture was neutralized with the addition of $2 \mathrm{~mL}$ of $20 \%$ (v/v) aqueous $\mathrm{Na}_{2} \mathrm{CO}_{3}$ solution and left at room temperature for $15 \mathrm{~min}$ until the characteristic blue colour developed. Absorbance at $725 \mathrm{~nm}$ was measured with UV-Vis spectrophotometer (UVVis Cary 60, Agilent Technologies, USA) against a blank. The total phenolic content was 
determined by means of a calibration curve prepared with gallic acid and expressed as mg of gallic acid equivalents (GAE) per $100 \mathrm{~g}$ of corn cob.

Antioxidant Capacity (AC). Antioxidant capacity was directly carried out on aliquots of the PAE and PHAE extracts as above reported for polyphenol quantification. REC antioxidant capacity was assessed starting from $5 \mathrm{~g}$ of REC extracted with $100 \mathrm{~mL}$ of $70 \%$ acetone for $6 \mathrm{~h}$ at room temperature. The radical scavenging activity was measured according to the ABTS $[2,29-$ azinobis-(3-ethylbenzothiazoline-6-sulfonic acid)] method described by Pellegrini et al. ${ }^{33}$ Briefly, the $\mathrm{ABTS}^{\cdot+}$ radical solution was generated by reaction of a $7 \mathrm{mM}$ solution of $\mathrm{ABTS}$ in water with $2.45 \mathrm{mM}$ of $\mathrm{K}_{2} \mathrm{O}_{8} \mathrm{~S}_{2}$ (in darkness at room temperature for $16 \mathrm{~h}$ ). The blue-green $\mathrm{ABTS}^{+}$solution was diluted with $50 \%$ ethanol until it reached an absorbance of $0.700 \pm 0.020$ at $734 \mathrm{~nm}$, measured with a UV-Vis spectrophotometer (UV-Vis Cary 60, Agilent Technologies, USA). Trolox was used as the antioxidant standard. Extracts were diluted appropriately with $50 \%(\mathrm{v} / \mathrm{v})$ ethanol. The reaction was carried out using $100 \mu \mathrm{L}$ extracts, or Trolox standard solution, plus $3,900 \mu \mathrm{L}$ of radical solution. The decrease of absorbance was monitored at $734 \mathrm{~nm}$ after $15 \mathrm{~min}$. The results were expressed as mmol Trolox equivalents (TE) antioxidant capacity $100 \mathrm{~g}^{-1}$ corn cob.

Anti-inflammatory properties. To test the anti-inflammatory properties of PHAE extract, the cells from human intestinal epithelial (Caco-2 cells) (ECACC 86010202, Public Health England) were used according to the method described in our previous work. ${ }^{32}$ Prior to the assay, PHAE was dried in a rotatory vapor to obtain the residual powder, subsequently dissolved in Dulbecco's Modified Eagle's Medium (DMEM). In order to evaluate the anti-inflammatory property of PHAE extract, the Caco-2 cells were simultaneously incubated with IL-1 $\beta$ (20 ng mL $\mathrm{m}^{-1}$ ) and anthocyanins-rich extract for 2 hours. Cells incubated only with IL-1 $\beta$ were 
considered as the control whereas the intact cells (considered as blank) were used to measure the cells' viability. Effects of the anthocyanin molecules on inflammatory cytokines were measured through the fold changes in IL-8 cytokine gene expression quantified by Real Time-PCR.

A concentration of total anthocyanin content of $25 \mu \mathrm{g} \mathrm{mL}^{-1}$ was considered for the tested samples. CyG standard was used as the positive control. For each sample the treatment was performed in three biological replicates.

\section{Dyeing process, colour strength and fastness.}

PAE was employed as a natural dyestuff for dyeing cotton $\left(240 \mathrm{~g} \mathrm{~m}^{-2}\right)$ and wool $\left(190 \mathrm{~g} \mathrm{~m}^{-2}\right)$ fabrics.

Cotton fabric pretreatment. Before dying cotton, the fabric was put through a pretreatment developed by Wang et al., ${ }^{30}$ by soaking with succinic acid and sodium hypophosphite $\left(\mathrm{NaH}_{2} \mathrm{PO}_{2}\right)$ at the same concentration $\left(20 \mathrm{~g} \mathrm{~L}^{-1}\right)$. The impregnated fabric was dried for a short time (4 min in total) at $90^{\circ} \mathrm{C}$, then $180^{\circ} \mathrm{C}$.

Cotton and wool mordanting and dyeing. Dyeing was performed as indicated previously in dye-tests $^{30}$, with minor revisions, adopting a fabric to liquor ratio of 1:50 (w/v). Alum (i.e., $\operatorname{AlK}\left(\mathrm{SO}_{4}\right)_{2} \cdot 12 \mathrm{H}_{2} \mathrm{O}$, cream of $\left.\left.\mathrm{KO}_{2} \mathrm{CCH}(\mathrm{OH}) \mathrm{CH}(\mathrm{OH}) \mathrm{CO}_{2} \mathrm{H}\right)\right)$, or tin salt $\left(\mathrm{SnCl}_{2}\right)$ were used as mordants and dissolved directly in the dye bath (10\% weight of fabric) to obtain PAE+Alum and PAE+Tin treatments, respectively. The procedure was conducted at $60{ }^{\circ} \mathrm{C}$ for 1 hour. The dyed fabrics were then rinsed with cold water and finally dried at room temperature overnight. 
Colour analysis. Dyed fabrics colour data were evaluated by CIELAB parameters detected with a tri-stimulus colorimeter (Croma Meter Cr 400 Konica Minolta, Nieuwegein, Netherlands) instrument (D65 illuminant standard, $10^{\circ}$ standard observer). In CIELAB colour space, colours are designated in coordinates, $\mathrm{L}^{*}$ coincides to brightness $(100=$ white, $0=$ black $)$, $\mathrm{a}^{*}$ to the redgreen coordinate $($ positive sign $=$ red, negative sign $=$ green $)$, and $b^{*}$ to the yellow-blue coordinate $($ positive sign $=$ yellow, negative sign $=$ blue $) ; C^{*}$ is the quantitative parameter of the chroma of the colour, and $\mathrm{h}^{*}$ is the quantitative parameter of the hue of the colour. Colour strength $(\mathrm{K} / \mathrm{S})$ for dyed samples was determined according to the Kubelka-Munk equation. ${ }^{30}$

Light fastness. Light fastness of dyed cotton and wool fabrics was measured according to an internal method derived from ISO standard method 105-B02 (2014). The samples were exposed with Solarbox 1500 (Erichsen GmbH \& Co., Hemer, DE), a tabletop large test chamber equipped with 1500-Watt Xenon lamp of correlated colour temperature $5500{ }^{\circ} \mathrm{K}$ to $6500{ }^{\circ} \mathrm{K}$, and irradiance control. The light of the Xenon lamp was filtered with UV $310+$ IR filters, light exposure time $48 \mathrm{~h}$. The light fastness test was assessed against to the standard Blue-scale reference and the values assigned starting from 1 (poor) to 8 (excellent).

Washing fastness. Washing fastness of cotton and wool dyed fabrics was evaluated according to standard method ISO 105-C02 (1989) with some modifications. Fabrics were washed at $50{ }^{\circ} \mathrm{C}$ for $45 \mathrm{~min}$ using water solution (1:50 w/v) of neutral detergent (Green Oasis brand, ICEFOR, Italy) $10 \mathrm{~g} \mathrm{~L}^{-1}$. Fabrics were subjected to three laundering cycles with interposed rinsing and drying. After tests, the colour changes were related to the standard grey-scale (marks $1-5 ; 1=$ poor, 5 = excellent). 


\section{Characterization of Residual Exhausted Cob.}

The exhausted corn cob material was characterized for its water holding capacity (WHC) and fibre detergent analysis in order to assess its ability to act as animal bedding in comparison to commercial corn cob products litter (CCL) (Lettosan Croci, Va, Italy)

The WHC was characterized following EN methodology (EN 13041, 2012). The neutral detergent fibre (NDF), cellulose and lignin contents in the corn cob dry matter were estimated using the fibre detergent method, determined according to protocols developed by Ankom Technology (ANKOM Technology Corporation, Fairpoint, NY), based on the work of Goering and Van Soest. ${ }^{34}$

For $\mathrm{pH}$ measurement, both raw material and REC (20 g) were mixed with $40 \mathrm{~mL}$ of deionized water for $30 \mathrm{~min}$ stirring, filtered and used for direct $\mathrm{pH}$ measurement.

To test halochromic properties REC was exposed to acidic and alkaline buffers. Two buffer solutions, at pH 5.0 (0.4 M of sodium acetate buffer) and $\mathrm{pH} 8.0$ (0.01 M TRIS-HCL buffer), were prepared and used to wet dry REC, then after $10 \mathrm{~min}$ it was photographed under natural light.

Informatic tools. Statistical analyses were conducted using the software IBM SPSS 25, (IBM Corp. Released 2017. IBM SPSS Statistics for Windows, Version 25.0. Armonk, NY: IBM Corp). In particular, one-way ANOVA analyses were carried out with a significance threshold set at 0.05 . Multiple comparisons were performed with the Duncan and Gabriel methods. 


\section{- Results and Discussion}

\section{Anthocyanins content in feedstock.}

The massive extraction of anthocyanins from dry raw material was conducted to detect the total amount of pigments (TAC) present in the corn cob. Both solvents used, i.e., $50 \%$ ethanol and 70\% acetone, gave similar anthocyanins content, i.e., $854 \pm 24$ and $931 \pm 44 \mathrm{mg}$ CyG eq. $100 \mathrm{~g}^{-1}$, respectively (Table 1$)$.

Table 1.Phytochemicals contents and antioxidant activity for corn cob and derived extracts

\author{
TAC \\ (mg CyG eq. $\left.100 \mathrm{~g}^{-1}\right)$ \\ (mg GAE $\left.100 \mathrm{~g}^{-1}\right)$
}

Antioxidant Activity (mmol TE $100 \mathrm{~g}^{-1}$ )

\section{Conventional \\ extraction}

EtOH extract

Acetone extract

$$
854 \pm 24 a
$$

$931 \pm 44 \mathrm{a}$

\section{Biorefinery products ${ }^{c}$}

PAE

PHAE

REC

$\operatorname{CCL}^{\mathrm{d}}$

$$
\begin{aligned}
& 310 \pm 18 b \\
& 284 \pm 17 b \\
& 183 \pm 15 c
\end{aligned}
$$

$\begin{array}{ll}1,674 \pm 127 \mathrm{a} & 5.35 \pm 0.47 \mathrm{a} \\ 1,212 \pm 98 \mathrm{~b} & 4.76 \pm 0.52 \mathrm{~b}\end{array}$

$3.36 \pm 0.17 \mathrm{c}$

$419 \pm 79 d$

$2.16 \pm 0.25 d$

$441 \pm 21 d$

$1.97 \pm 0.10 \mathrm{~d}$

$303 \pm 34 \mathrm{e}$

$0.70 \pm 0.04 \mathrm{e}$

aTAC: Total Anthocyanins Content; ${ }^{\mathrm{b}}$ Total polyphenols; ${ }^{\mathrm{c}}$ products obtained during sequential extraction process such as described in Figure 1. ${ }^{\mathrm{d}} \mathrm{CCL}$ : commercial corn cob litter for pets (CCL), followed by the same letter, within each column, are not significantly different (Tukey test, $\mathrm{p}<0.05)$. 
These values fell into the range reported in the literature, i.e., $202-4,600 \mathrm{mg} 100 \mathrm{~g}^{-1}$ corn $\operatorname{cob}^{35-37}$ in which variability depended on both corn variety ${ }^{9,10}$ and pedoclimatic conditions. Light (photoperiod length) and temperature, have been reported to affect anthocyanins content when varieties adapted to tropical areas are cropped in a temperate climate. ${ }^{8}$

\section{Biorefinery first step: PAE for dyeing.}

The first product of the biorefinery process, PAE, yielded $310 \mathrm{mg}$ CyG equivalent $100 \mathrm{~g}^{-1} \mathrm{corn}$ cob (Table 1$)$ that represented about one third of TAC $(36 \%)$ reached by conventional extraction with $50 \%$ ethanol. The increase of temperature positively affected the recovery of anthocyanins by using water solvent and the optimum extraction temperature was reached at $70{ }^{\circ} \mathrm{C}$ (Figure S1). Exceeding this temperature gave no significant increase in anthocyanins yield. Moreover, extraction time was established at $30 \mathrm{~min}$, as no differences occurred when tests were prolonged to 60 min, as already observed. ${ }^{31}$

In PAE, from a qualitative point of view, it emerged that glycosylated anthocyanins were represented mainly by three aglycones: cyanidin, present as $\mathrm{CyMG}$ and $\mathrm{CyG}$, pelargonidin as PlG and PIMG and peonidin, as PnG and PnMG (Table 2, chromatogram in Figure S2). In addition, minor anthocyanins, constituting less than $10 \%$ of TAC, were found but not clearly identified. These compounds, probably, can be ascribed to hypothetical dimalonyl- or ethylmalonyl-derivatives. ${ }^{38}$ Chromatogram in Figure S2 showed that there were no free anthocyanidins in water extract, indicating that the mild extraction conditions adopted did not 
affect anthocyanins integrity. In fact, free aglycones are normally obtained by basic and acid hydrolysis.

The anthocyanin profile of the PAE (Figure S2) matched that found in the literature for similar plant material. ${ }^{39,40} \mathrm{CyG}$ and $\mathrm{CyMG}$ were the two major anthocyanins since they accounted for about $60 \%$ of the total anthocyanins present (Table 2), and, among them, CyMG was two-fold CyG. In corn, anthocyanins acylation occurs prevalently through the linkage with malonic acid, which may be present as mono, di-, or tri-malonyl, glycosylated.

\begin{tabular}{|c|c|c|c|}
\hline anthocyanins & PAE & $\begin{array}{l}\text { PHAE } \\
\text { (\% TAC }\end{array}$ & REC \\
\hline $\mathrm{CyG}$ & 22.2 & 31.4 & 25.4 \\
\hline $\mathrm{PlG}$ & 4.6 & 6.7 & 5.6 \\
\hline PnG & 7.2 & 9.3 & 7.9 \\
\hline CyMG & 40.7 & 30.3 & 34.1 \\
\hline PlMG & 6.8 & 6.8 & 6.1 \\
\hline PnMG & 9.0 & 6.8 & 7.6 \\
\hline Others & 9.7 & 8.7 & 13.3 \\
\hline
\end{tabular}


The presence of - $\mathrm{COOH}$ group(s) and their dissociation forms promote the protonated form of the flavylium cation of the anthocyanins (Figure S3) which protects them from colour degradation, deriving from the increase in $\mathrm{pH}$. Lower $\mathrm{pH}$ values promote anthocyanins stability, solubility in water and brilliant red colour. ${ }^{28}$ Effectively, different anthocyanin forms exist in equilibrium, and the increase of $\mathrm{pH}$ favors the deprotonation or hydration of the flavylium cation, towards molecular forms that lose stability and become colourless (carbinol pseudobase and chalcone) with respect to the coloured flavylium cation (red) and the quinoidal base (blue) ${ }^{41}$ These different pigment chemical forms coexist in PAE that showed a $\mathrm{pH}$ which was not extremely acidic ( $\mathrm{pH}$ of corn cob extract of about 4.2). However, the prevalence in the extract of the acylated anthocyanins (malonyl and dimalonyl derivates) (66\% of TAC) (Table 2), can favor the maintenance of colour stability. Despite $\mathrm{pH}$ conditions, anthocyanin stability is also affected by heat, and the pigment is easily converted into the colourless chalcone form during prolonged heating. ${ }^{42}$

Water extraction from the cob also allowed the solubilisation of other phenolic compounds. In PAE, TP content was of $708 \pm 14 \mathrm{mg} \mathrm{GAE} 100 \mathrm{~g}^{-1}$ corn cob (Table 1) that represented the major moiety $(45 \%)$ of the total sequentially extracted polyphenols, i.e., $(\mathrm{PAE}+\mathrm{PHAE}+\mathrm{EC})=1,568$ mg GAE $100 \mathrm{~g}^{-1}$ (Table 1), with those for PHAE and REC of $419 \pm 79 \mathrm{mg} \mathrm{GAE} 100 \mathrm{~g}^{-1}$ and 441 $\pm 21 \mathrm{mg}$ GAE $100 \mathrm{~g}^{-1}$ corn cob, respectively. Phenolic compounds found in PAE might have important roles in dyeing, for instance by contribution to maintain anthocyanin colour stability (copigmentation phenomena involving polyphenols) $)^{43}$ or, together with anthocyanins extracted, by implementing UV radiation absorption ${ }^{44}$ and promoting a protective function in the dyed fabric against solar radiation damage. Moreover, polyphenols, which include the anthocyanin family, can act as antioxidants or free radical scavengers, thus preventing oxidative stress. In this 
regard, many authors have reported that also anthocyanins may act with protective effect on biological oxidative damage. ${ }^{45,46}$ Generally, the pigmented kernel exhibits higher antioxidant activity than non-pigmented corn. ${ }^{25,47}$ Antioxidant activity was associated with the presence of bioactive compounds inclusive of anthocyanins and soluble phenols. The use of different solvents in the extraction stream induced slight differences in antioxidant activity (Table 1). Nevertheless, PAE resulted in better antioxidant activity in comparison with the PHAE, because of the presence in the extract of more water-soluble phenols rather than the anthocyanins concentration.

Dyeing properties. PAE, once obtained, was directly employed for eco-friendly natural dyeing on cotton and wool fabrics (Figure 1). PAE dye concentration corresponded to $350 \mathrm{mg} \mathrm{L}^{-}$ ${ }^{1}$ anthocyanins and tincture tests were conducted using only PAE or by adding mordanting agents (PAE+Alum, PAE+Tin) to implement and improve the fixing of colour to natural fibres. To assess the quality of the dye, the colour strength $(\mathrm{K} / \mathrm{S})$, the changes in the original colour profile $\left(a^{*}, b^{*}, C^{*}, h^{*}\right)$ and the light and wash fastness of fabric dyed were explored (Table 3$)$.

Generally, protein fibres of animal origin have more affinity to natural dyes in comparison with cellulosic plant ones. In fact, dyed wool always showed a better colouring behaviour than cotton, which shows lower values of K/S and light-wash fastness. However, the choice to include cotton in dyeing trials with PAE is mainly due to the modification to which the fabric was subjected during a pre-treatment with succinic acid, as suggested by Wang et al. ${ }^{30}$, which enhanced the affinity of the cellulose substrate to dye, especially in the presence of a metal-salt based mordant. Particularly, the presence of tin in the dye bath improved the colour depth of the fabrics, measured by K/S value. The increase was of almost two-fold, for both cotton and wool with 
respect to other dyeing tests, i.e., in wool, PAE+Tin treatment exhibited the highest $\mathrm{K} / \mathrm{S}$ value (4.29) while PAE+Alum slightly affected K/S in comparison with mordant-free dyeing.

The addition of the metal salt in the dye bath caused a bathochromic shift in a visible range of red anthocyanins towards purplish red extract as already well described in dyeing with natural pigments. ${ }^{30,48}$ This chemical mechanism is known as metal copigmentation mediated by the complexation of anthocyanins with metals $(\mathrm{Cu}, \mathrm{Al}, \mathrm{Sn}, \mathrm{Fe})$, with the result that it increased anthocyanins' colour stability to temperature, light, oxygen and $\mathrm{pH} .{ }^{49}$ Among aglycones present in PAE, cyanidin, which has at least two free hydroxyl group in the B-ring (see anthocyanins molecule in Figure S3), are capable of metal chelation. In dyed fabrics the maximum absorption $\left(\lambda_{\max }\right)$ in the visible range (shown in Table 3 ) shifted from $518 \mathrm{~nm}$ of PAE to $528 \mathrm{~nm}$ for PAE+Alum $\left(\lambda_{\max }=10 \mathrm{~nm}\right)$ and to $549 \mathrm{~nm}$ for PAE + Tin $\left(\lambda_{\max }=31 \mathrm{~nm}\right)$. Moreover, PAE+Tin induced, in addition to colour stability, an enhanced colourant hyperchromic effect, as sustained by increases in absorbance value (data not shown).

The use of Tin mordant, besides enhancing colour strength such as suggested by the K/S parameters, (Table 3), i.e. K/S number increase with colouring strength, conferred on fabric dyes a shade difference. In addition, the use of this mordant affected the colour brightness parameter $\mathrm{L}^{*}\left(\mathrm{~L}^{*}\right.$ of $100=$ white, $\mathrm{L}^{*}$ of $0=$ black$)$. In particular, for cotton the presence of Tin determined a darkening of the colour, i.e. $\mathrm{L}^{*}$ value decreased from 56.69 for PAE and 59.8 for PAE + Alum to 40.9 for PAE + Tin. On the contrary, for wool the L* parameters indicated a slightly brightness increase, i.e. from 27.31 for PAE and 25.63 for PAE + Alum to 32.34 for PAE + Tin (Table 3). Interesting was also data relative to the colour hue, such as well resumed by $\mathrm{h}^{*}$ parameter, that increased a lot in presence of Tin mordant, i.e. 337.10 for cotton and 335.93 for wool. The formation of metal-anthocyanin complexes was suggested changing colours from 
reddish-purple to violet (Table 3 ), such as indicated by the modification of $b^{*}$ parameters (it indicates the yellow-blue coordinate: positive sign $=$ yellow and negative $\operatorname{sign}=$ blue), that assumed negative value, being the parameters $\mathrm{a} *$ that corresponded to the red-green coordinate $($ positive sign $=$ red and negative sign $=$ green $)$ unmodified, independently from the nature of the fabric. Otherwise, PAE+Alum dyed fabrics displayed the ability to keep the original colour characteristics of PAE mordant-free and in fact $b^{*}$ parameters did not change for both cotton and wool (Table 3).

No less important than colour characteristics are the colour fastness. The rating results of light and washing fastness are included in Table 3 and show that the addition of mordant was necessary to improve colour durability of the fabric dyed with PAE. Colour fastness to light showed that, once again, in wool PAE+Tin the rating increased from poor (1) to fair (3) in Bluescale grade, and this was an acceptable result, considering the susceptibility of the anthocyanins to the (sun)-light and the importance of their co-pigmentation as above described. Both cotton and wool dyed with anthocyanins-based PAE were gently washed with neutral anionic soap and after three cycles of laundering a good wash stability was shown for cotton ( 3 and 4 value for Alum and Tin, respectively) and better for wool fabrics (4-5 value). 


\section{Table 3. Dyed fabrics, colorimetric and fastness properties}

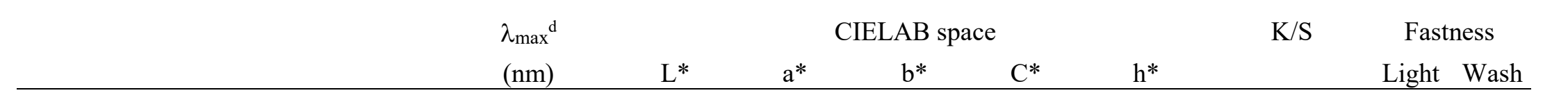

\section{Cotton}

Undyed

PAE $^{\mathrm{a}}$

PAE+Alum ${ }^{\mathrm{b}}$

$\mathrm{PAE}+\mathrm{Tin}^{\mathrm{c}}$

\section{Wool}

Undyed

$\mathrm{PAE}^{\mathrm{a}}$

$\mathrm{PAE}+$ Alum $^{\mathrm{b}}$

PAE+Tin

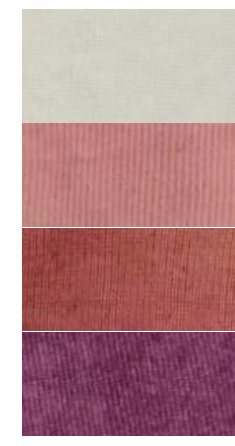

$\begin{array}{llllllllll} & 94.01 & -0.07 & 2.94 & 3.02 & 103.26 & & & \\ 281,518 & 56.69 & 25.61 & 3.15 & 25.80 & 27.02 & 1.61 & 1 & 1 \\ 283,528 & 59.80 & 23.48 & 3.34 & 23.71 & 28.10 & 1.98 & 1 & 3 \\ 278,549 & 40.90 & 23.47 & -9.91 & 25.47 & 337.10 & 3.54 & 3 & 4\end{array}$

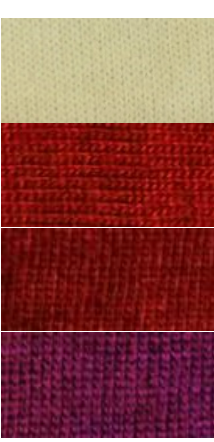

278,519

86.58

$-1.31$

15.10

15.16

94.94

278,529

27.31

22.42

8.20

23.88

20.09

278,529

25.63

22.92

8.63

24.45

20.64

278, 547

32.34

14.48

$-6.47$

$15.86 \quad 335.93$

$\begin{array}{ccc}1.98 & 1 & 2 \\ 2.10 & 2 & 4 \\ 4.29 & 3 & 4-5\end{array}$

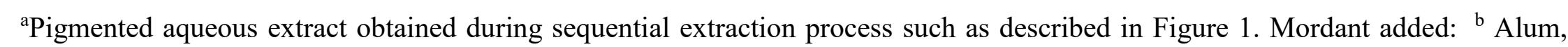
potassium aluminium sulphate, and ${ }^{\mathrm{c}}$ Tin salt, $\mathrm{SnCl}_{2} .{ }^{\mathrm{d}} \mathrm{Maximum}$ absorbance $(\mathrm{nm})$ in the UV-Visible range. 
In plants, anthocyanins may possibly limit photo-oxidative injury of the photosynthetic tissues of leaves and fruits by acting as a screen from high-energy light excesses, attenuating the incident radiation in visible and UV parts of the spectrum and scavenging reactive oxygen species. Anthocyanins preferably absorb in the visible green and ultraviolet (UV) regions. ${ }^{49}$ However, they exhibit a lower absorbance in the UV region in comparison with other colourless flavonoids and phenolic compounds. ${ }^{44}$ Outside the biological system, and according to previous studies, characteristic absorption spectra of specific anthocyanins extracted from purple corn cob (PAE), showed two regions in the UV-Vis (Figure 2).

The first region, peaking around $280 \mathrm{~nm}(\mathrm{UV}-\mathrm{B})$, is due to the presence of aromatic rings and is typical of all phenolic family compounds; the second long-wave band was situated in the 450$550 \mathrm{~nm}$ range (blue-green) and it was due to the flavylium cation. The maximum absorbance in the visible range varied for different aglycones, and the aglycone of $\mathrm{CyG}$, which was responsible for the reddish colouration of purple corn cobs, peaked at around $518 \mathrm{~nm}$. The same absorption spectrum was described for CyMG, which means that acylation did not substantially change the absorption characteristics of the pigment.

Natural dyed cloth can exert a role in the protection of human skin against the harmful effects of UV irradiation. Particularly in humans, it is widely accepted that there is an actual direct or indirect association between UV radiation and the development of skin cancer. ${ }^{50}$ 


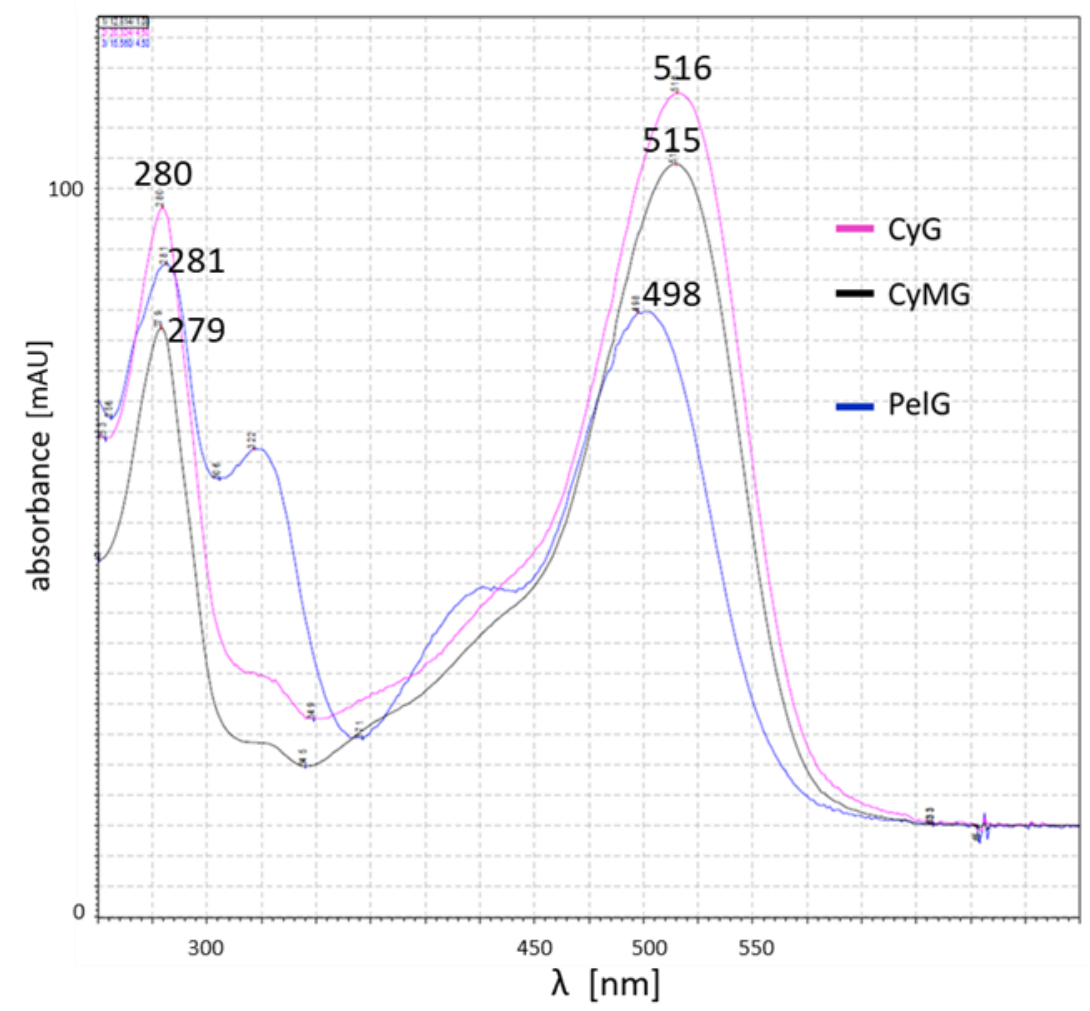

Figure 2. UV-VIS spectra with relative absorption maxima of some anthocyanins (CyG, CyMG, and P1G) founded in PAE and separated by HPLC-DAD.

As a covering factor, dyed fabrics can absorb an important moiety of UV radiation, greater than undyed ones. The protection efficiency, described by the Ultraviolet Protection Factor $(\mathrm{UPF})^{51}$, increased in those fabrics dyed with natural pigments. ${ }^{52,53}$ In our study, anthocyanins metal co-pigmentation induced, in the PAE + Tin dyeing solution, a shifting of the radiation absorbance $(\mathrm{nm})$ in the UV-visible range, i.e. $\lambda_{\max }$ shifted from $518 \mathrm{~nm}$ to $549 \mathrm{~nm}$ (Table 3 ), but it did not interfere with anthocyanins absorption in the UV range, i.e. $\lambda_{\text {max }}$ remained quite stable, i.e. from $281 \mathrm{~nm}$ to $278 \mathrm{~nm}$ (Table 3 \& Figure 2). Among numerous extracts of natural colourants, it has been demonstrated that fabrics coloured with red onion peel, rich in 
anthocyanins' aglycones (cyanidin, delphinidin, pelargonidin, and peonidin), showed an excellent UPF value (50+), in the presence or in the absence of mordant. ${ }^{54}$ PAE dyed fabrics could show the same important feature.

\section{Biorefinery second step: PHAE for nutraceuticals}

The extraction yield obtained showed that the anthocyanins water extraction was not an exhaustive extraction process (Table 1) and that about $64 \%$ of total anthocyanins (TAC) remained in the residual solids extracted (Figure 1). Therefore, aiming to recover as much as possible of the valuable biomolecules contained in the corn cob, a subsequent extraction with hydro-alcoholic solvent slightly acidified $(0.01 \% \mathrm{HCl})$ was performed, obtaining a second extract, i.e., PHAE, that accounted for 33\% of the total corn cob anthocyanins content (Figure 1), equal to $284 \mathrm{mg}$ CyG equivalent $100 \mathrm{~g}^{-1}$ (Table 1). PHAE showed a different anthocyanins pattern with respect to PAE (Table 2) and in particular, the CyG/CyMG ratio for PHAE (1.03) was higher than that estimated for PAE (0.54). It would seem that the acylated anthocyanidins forms (CyMG, PIMG and PnMG) were preferentially extracted by cold water during the first step, while the following hydro-alcoholic extraction acted preferentially on glycosylated but not acylated anthocyanins retrieval (CyG, PlG and PnG).

The antioxidant activity of extracts was investigated individually both for PAE and PHAE. However, considering the antioxidant activity per mg of anthocyanins, i.e., antioxidant efficiency, it appeared that PHAE contained anthocyanins which exhibited a better antioxidant performance than PAE (Table 1). Comparing anthocyanins composition of both extracts (Table

2), there was no clear evidence that the acylation of anthocyanins can improve antioxidant 
capacity. Nevertheless, it has been shown that the number of hydroxyl groups on the B-ring of the chemical structure of anthocyanidins could be responsible for their antioxidant activity (Chen et al., 2018). A linear relationship was observed in both extracts between antioxidants and total polyphenols that included the anthocyanins moiety $(\mathrm{r}=0.92, \mathrm{p}<0.05 ; n=3)$, but it would seem that the antioxidant efficiency of PAE was higher compared to PHAE.

This might be due to the fraction of non-pigmented polyphenols extracted preferentially during the first extraction in water. The second extraction with ethanol solution became necessary to obtain an additional $33 \%$ of yield since the water alone was not effective to obtain this result (data not shown). Furthermore, ethanol is a non-toxic solvent and water-alcohol solution reduces the time and cost to concentrate the biomolecules.

In PHAE the yield of total polyphenols was almost halved compared to the amount found in PAE while TAC was more or less the same. Thus, in PHAE the antioxidant activity might be mostly ascribable to the TAC.

The anti-inflammatory properties of purple corn anthocyanins have recently been reported by Zhang et al. ${ }^{55}$ Purple corn anthocyanins have shown an effective down-regulation on the secretion levels of pro-inflammatory cytokines such as IL-6 and TNF- $\beta$ in a wide range from -2.5 to $-60.1 \%$ and -9.7 to $-64.8 \%$, respectively.

PHAE was investigated for its anti- inflammatory effects (Figure 3 ) on the IL-8 cytokine production in the Caco-2 cells stimulated by IL-1 $\beta$, potent pro-inflammatory cytokine. As shown, in response to cytokine IL- $1 \beta$ treatment, the expression of IL-8 gene was increased up to 63-fold, whereas in the presence of the anthocyanins-rich extract (IL-1 $\beta+\mathrm{PHAE})$, the gene expression was down-regulated 10-fold, similarly to the effect given by CyG (IL-1 $\beta+\mathrm{CyG}(\mathrm{std})$ ). 
The PHAE and CyG can decrease the cytokine secretion significantly $(p<0.05)$ in the stimulated Caco-2 cells.

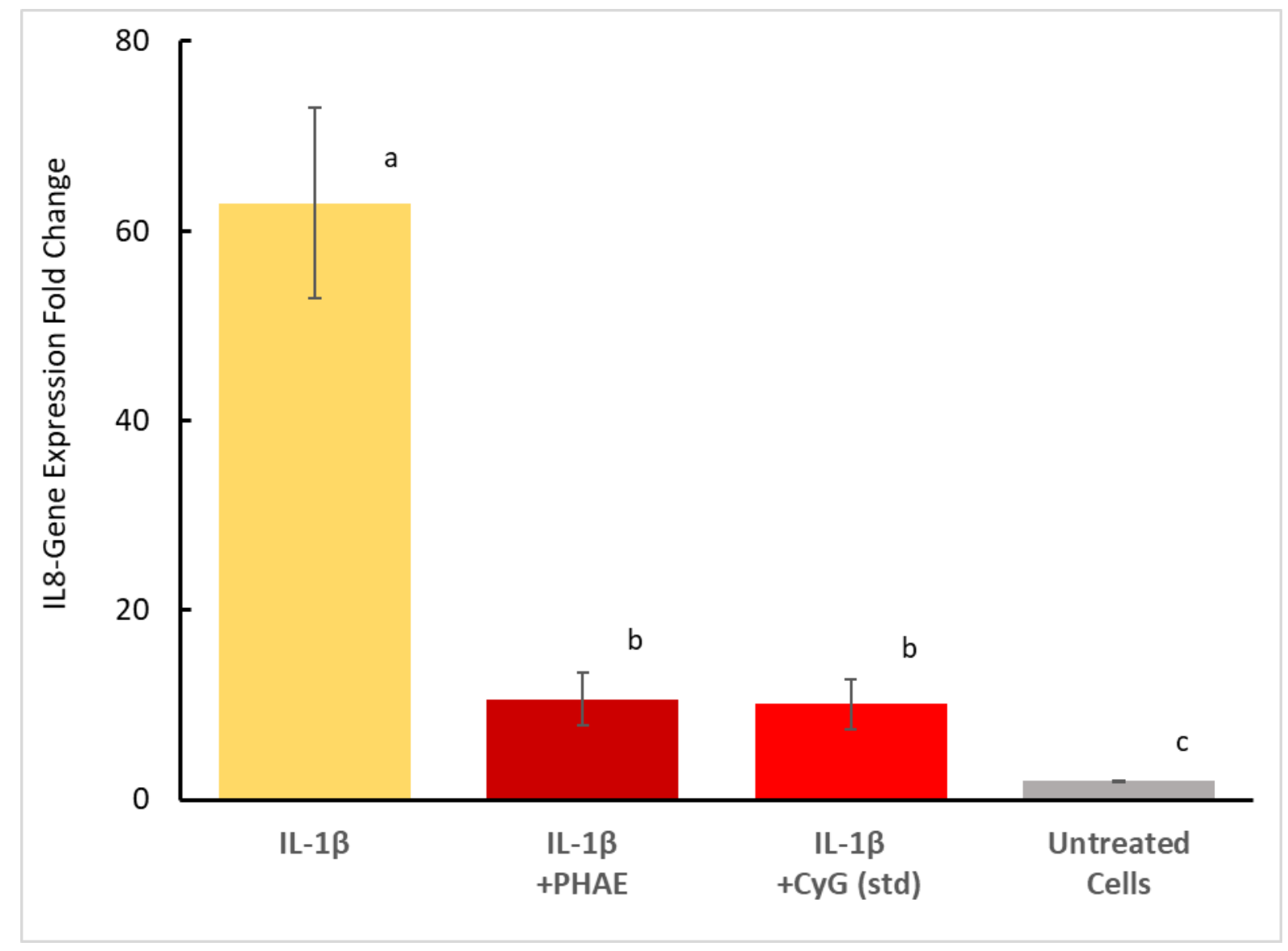

Figure 3. Immunosuppressive effects of PHAE and CyG pure standard $\left(25 \mu \mathrm{g} \mathrm{mL}^{-1}\right)$ on IL-8 gene expression in the Caco-2 cells stimulated by pro-inflammatory cytokine IL-1 $\beta$, expressed as the change folds. Untreated cells are not stimulated. Bars with different letters are significant different (Duncan's test, $\mathrm{p}<0.05$ ).

The characterization of pigmented corn cob revealed that the PHAE anthocyanins-rich extract (Table 2) was represented by the anthocyanins in glycosyl and acyl bound forms. In fact, in the 
hydro-alcoholic extract, anthocyanins $\mathrm{CyG}$ and CyMG were present at the same relative contents, which could suggest a lower efficiency for CyMG than CyG to suppress the inflammation within the Caco-2 cells, which propose that the glycoside form of cyanidin has a greater anti-inflammatory property than its malonyl form. ${ }^{56}$ Zhang et al. ${ }^{57}$ investigated the associations between various glycosylated anthocyanins and phenolic compounds in the corn and anti-inflammatory markers, and found that the $\mathrm{CyG}$ was more correlated to suppressing the inflammatory cytokines than CyMG. The same results were observed for the PIG and PIMG in the pigmented corn. All this implies that the presence of glycosyl-bound anthocyanins (but not the malonyl moiety) facilitate the regulation of inflammatory responses and the transcription of the modulatory signaling pathways in the cells. Anthocyanins from pigmented corn not only have suppressing activity on the inflammatory cytokine gene expression, but also have regulatory effects on the enzymes related to the inflammation. The strong anti-inflammatory properties of $\mathrm{CyG}$ at $20 \mu \mathrm{g} \mathrm{mL}^{-1}$ have been reported previously in the macrophages induced by lipopolysaccharides, in which it has inhibited nitric oxide (NO) production. ${ }^{58}$ Two main anthocyanins in the pigmented corn, $\mathrm{CyG}$ and $\mathrm{PlG}$, showed the highest inhibitory effect on inducible nitric oxide synthase (iNOS) expression $(-28.9 \%)$, and the greatest potency in suppressing cyclooxygenase-2 (COX-2) expression $(-51.8 \%) .{ }^{55}$ However, it was noteworthy that other flavonoids rather than anthocyanins, usually found in the hydro-alcoholic extracts of pigmented corn cob, collaborated towards the overall anti-inflammatory properties. In this regard, quercetin, rutin and luteolin, have been reported for their active anti-inflammatory activity in the pigmented corn. ${ }^{55}$ 
The mechanism of the anti-inflammatory property of pigmented corn anthocyanins has been described through the inhibiting of the protein complex NF- $\kappa$ B which is an important family of transcription factors playing a pivotal role in the regulation of the immune system. ${ }^{55}$

These results illustrate how PHAE can supply nutraceutical and functional molecules that could be supplemented to improve the nutritional value of final products, i.e. food/feed.

\section{REC utilization as animal bedding.}

Residual exhausted cob (REC) was proposed to be used as animal bedding (e.g., for cats, rodents, birds and reptiles), that after its use can be separately collected with organic food waste and addressed to anaerobic digestion and/or composting producing biogas and biofertilizers, thus closing the biomass cycle, with zero waste production.

Chemical and physical characteristics of REC were compared with those of a commercial corn cob litter (Table 4).

\section{Table 4. Comparison between REC and homologous commercial cob litter}

\begin{tabular}{cccccccc} 
& $\mathrm{pH}$ & $\mathrm{WHC}^{\mathrm{a}}$ & $\mathrm{DM}^{\mathrm{b}}$ & Ash & $\mathrm{NDF}^{\mathrm{c}}$ & Cellulose & Lignin \\
& & & & $\left(\mathrm{g} 100 \mathrm{~g}^{-1} \mathrm{DM}\right)$ & & \\
\hline REC & $4.2^{\mathrm{d}}$ & 73.4 & 95.1 & 0.81 & 93.3 & 27.3 & 23.1 \\
$\mathrm{CCL}$ & 5.9 & 62.8 & 96.2 & 1.25 & 94.9 & 33.9 & 14.3
\end{tabular}


${ }^{a}$ WCH: water holding capacity. ${ }^{b} \mathrm{DM}$ : dry matter. ${ }^{\mathrm{c}} \mathrm{NDF}$ neutral detergent fibre. ${ }^{\mathrm{d}}$ The data are mean values obtained from three independent experiments. Standard deviations were not more than $10 \%$ for each determination.

Chemical characteristic of residual exhausted cob (REC) and commercial animal bedding were very close. In particular dry matter and ashes content were quite identical (Table 4) as well as the presence of fibre, i.e. cellulose and hemicellulose. However, the water holding capacity (WHC), that represents an important parameter since the retention of liquid is greatly appreciated for animal bedding, was higher than that measure for commercial product, i.e. $73.4 v$ s. $62.9{\mathrm{~g} 100 \mathrm{~g}^{-1}}^{-1}$ DM. Moreover, commercial corn cob litter for pets (Table 1) shown the minor antioxidant activity due low total polyphenols (TP) concentration and a total absence of anthocyanins.

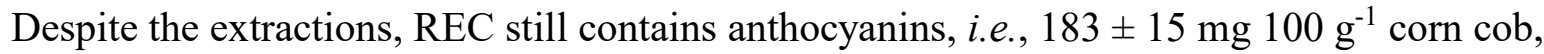
which could not be removed (see the purple colour in Figure 4, i.e. control), and their positive effect might be exploited. Cyanidin (in the form of $\mathrm{CyG}$ and $\mathrm{CyMG}$ ) is the aglycone most representative in REC (Table 2).

A previous study ${ }^{59}$ reported a strong antimicrobial activity (against Salmonella enteritidis, Staphylococcus aureus, and Candida albicans) exerted by extracts of a purple corn hybrid. Thus, thanks to the inhibition of bacterial activity, the presence of residual anthocyanins in REC may be useful, e.g., to limit the release of unpleasant odours from the litter.

The colour change property of anthocyanins extract, because of $\mathrm{pH}$ variations, has been already exploited as potential natural $\mathrm{pH}$ indicators in film packaging applications. ${ }^{60,61}$ Similarly, we have tested the halochromic properties of REC, soaking it with $\mathrm{pH}$ buffers at units $5 \& 8$, to simulate the limits of $\mathrm{pH}$ range of animal urine (Figure 4). 


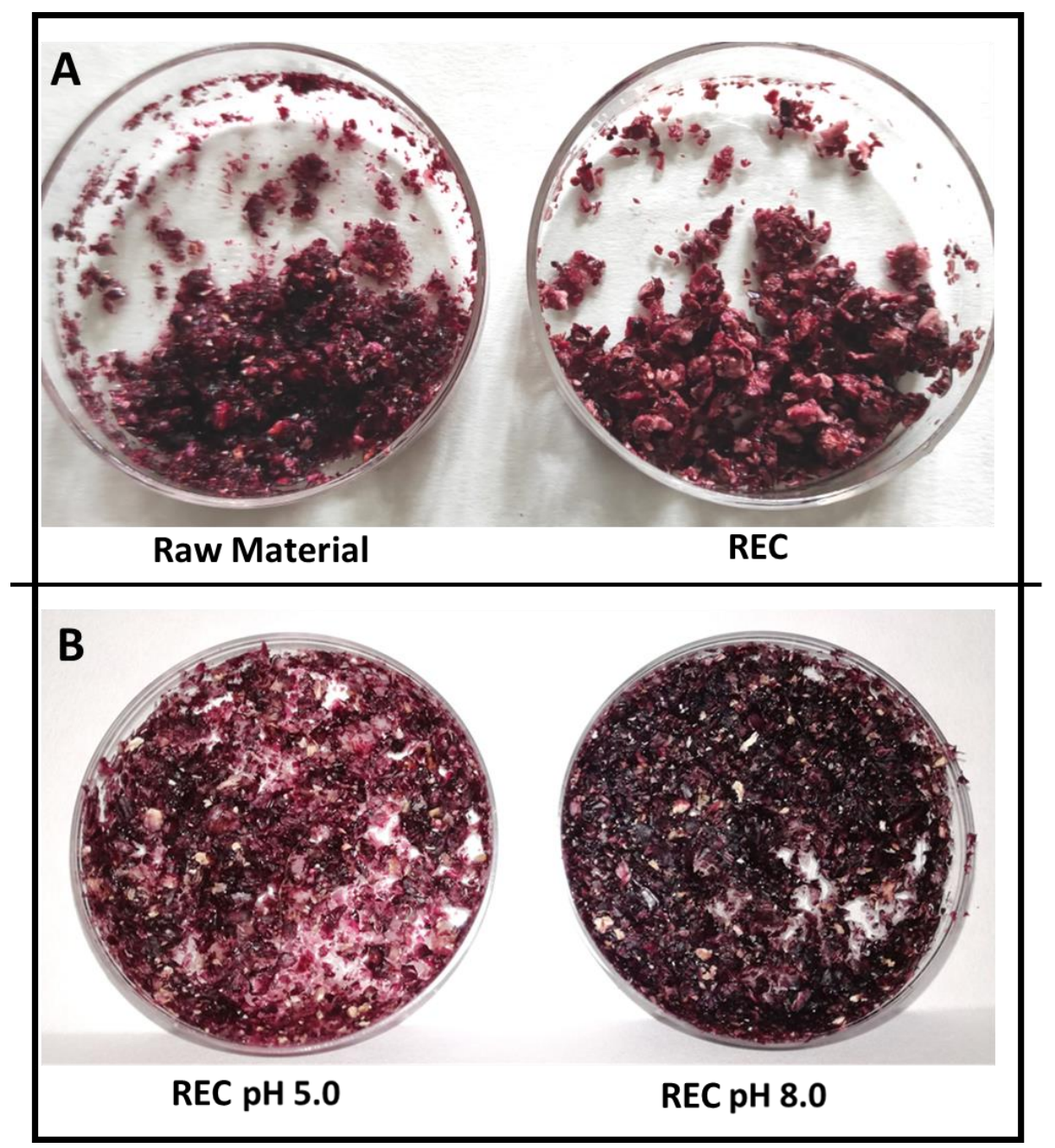

Figure 4. Halochromic property of purple corn cob: (A) raw material before biorefinery process (top left) and residual exhausted cob (REC) (top right) soaked with water ( $\mathrm{pH}$ of 4.2); (B) REC soaked with different $\mathrm{pH}$ buffers: $\mathrm{pH} 5.0$ (bottom left) and $\mathrm{pH} 8.0$ (bottom right).

The result showed a perceptible REC colour change between the two treatments (pH $5.0 \mathrm{vs}$ $\mathrm{pH} 8.0$ in Figure 4B). The prevalence of the colourless chalcone form of anthocyanins pigment at these $\mathrm{pH}^{41}$ associate to ligno-cellulosic matrix confer a brownish colour (background colour) which slightly mask the color change. This is evident in the test with distilled water (Figure 4A) in which corn cob before and after extraction did not show differences in $\mathrm{pH}$ (4.2) and therefore in colour. Nevertheless, at $\mathrm{pH} 8.0$ the change in colour was more marked, since the quinone- 
base form of anthocyanins became the main molecular form, shifting the REC colour towards green and blue shades. The use of the REC as a pH indicator could be useful to pet owners to evaluate when to replace the litter box or even can give, in some cases, indications on the state of the animal's health.

\section{- Conclusion}

Purple corn cob represents a sustainable source of high added-value products recoverable by a biorefinery approach, according to the concept that the bioeconomy must be restorative and regenerative. The proposed biorefinery concept was analyzed in detailed aspects of the extraction and the potential for subsequent valorization of the products, and useful data were obtained.

Water extraction gave an anthocyanins-rich extract (PAE) fraction usable as a natural dye, showing, also, UV protection of the dyed clothes. Consumers can take advantage of textile products of excellent aesthetic appearance and also for their sustainability since they are dyed with natural pigments, with good durability and acceptable stability. The PHAE extract subsequently extracted demonstrated a good anti-inflammatory property and it can be used in food/feed or beverages to enhance health benefits.

Subsequently the purple lignocellulosic solid residue (REC) can be considered as a feasible animal bedding for pets, which may also include a $\mathrm{pH}$ indication capacity, and which can be compostable once discharged, nulling the waste produced.

Further studies needed in order to provide more data with regards biorefinery process of purple corn cob, i.e. mass balance, energy efficiency including cost analysis. 


\section{Associated Content}

\section{SI Supporting Information}

Preliminary experiments on water extraction anthocyanins (based on temperature and sampleto-solvent ratio); HPLC chromatograms of corn cob extracts; chemical structure of anthocyanins.

\section{Funding sources}

This work was supported in part by the PASTEL project ('Pigmented maize cobs waste as an environmentally friendly solution to dye natural fibres' ID 2017-0973) financed by Fondazione CARIPLO.

\section{Acknowledgements}

A very special thank goes to the fireman and biologist Dr. Sara Zangarini for the artistic handmade drawing (graphical abstract in Table of Content) realized during the first coronavirus crisis in Bergamo, Italy. 


\section{- References}

(1) Mansour, R. Natural Dyes and Pigments: Extraction and Applications. In Handbook of Renewable Materials for Coloration and Finishing; John Wiley \& Sons, Inc., 2018; pp 75102. https://doi.org/10.1002/9781119407850.ch5.

(2) Séquin-Prey, M. The Chemistry of Plant and Animal Dyes. J. Chem. Educ. 1981, 58 (4), 301-305. https://doi.org/10.1021/ed058p301.

(3) Alexandra Pazmio-Durán, E.; Giusti, M. M.; Wrolstad, R. E.; Glória, M. B. A. Anthocyanins from Banana Bracts (Musa X Paradisiaca) as Potential Food Colorants. Food Chem. 2001, 73 (3), 327-332. https://doi.org/10.1016/S0308-8146(00)00305-8.

(4) Manian, A. P.; Paul, R.; Bechtold, T. Metal Mordanting in Dyeing with Natural Colourants. Color. Technol. 2016, 132 (2), 107-113. https://doi.org/10.1111/cote.12199.

(5) Bechtold, T.; Mussak, R.; Mahmud-Ali, A.; Ganglberger, E.; Geissler, S. Extraction of Natural Dyes for Textile Dyeing from Coloured Plant Wastes Released from the Food and Beverage Industry. J. Sci. Food Agric. 2006, $86 \quad$ (2), 233-242. https://doi.org/10.1002/jsfa.2360.

(6) Petroni, K.; Pilu, R.; Tonelli, C. Anthocyanins in Corn: A Wealth of Genes for Human Health. Planta 2014, 240 (5), 901-911. https://doi.org/10.1007/s00425-014-2131-1. 
(7) Dahham, S. S.; Ali, N.; Tabassum, H.; Khan, M. Studies on Antibacterial and Antifungal Activity of Pomegranate (Punica Granatum L.). Am. Eurasian J. Agric. Environ. Sci. 2010, $9(3)$.

(8) Tsoyi, K.; Hyung, B. P.; Young, M. K.; Jong, I. L. C.; Sung, C. S.; Hae, J. S.; Won, S. L.; Han, G. S.; Jae, H. L.; Ki, C. C.; Hye, J. K. Protective Effect of Anthocyanins from Black Soybean Seed Coats on UVB-Induced Apoptotic Cell Death in Vitro and in Vivo. J. Agric. Food Chem. 2008, 56 (22). https://doi.org/10.1021/jf802112c.

(9) Monroy, Y. M.; Rodrigues, R. A. F.; Sartoratto, A.; Cabral, F. A. Extraction of Bioactive Compounds from Cob and Pericarp of Purple Corn (Zea Mays L.) by Sequential Extraction in Fixed Bed Extractor Using Supercritical CO2, Ethanol, and Water as Solvents. $J$. Supercrit. Fluids 2016, 107, 250-259. https://doi.org/10.1016/j.supflu.2015.09.020.

(10) Fernandez-Aulis, F.; Hernandez-Vazquez, L.; Aguilar-Osorio, G.; Arrieta-Baez, D.; Navarro-Ocana, A. Extraction and Identification of Anthocyanins in Corn Cob and Corn Husk from Cacahuacintle Maize. J. Food Sci. 2019, 84 (5), 954-962. https://doi.org/10.1111/1750-3841.14589.

(11) Yusuf, M.; Shahid, M.; Khan, S. A.; Khan, M. I.; Islam, S. U.; Mohammad, F.; Khan, M. A. Eco-Dyeing of Wool Using Aqueous Extract of the Roots of Indian Madder (Rubia Cordifolia) as Natural Dye. J. Nat. Fibers 2013, 10 (1), 14-28. https://doi.org/10.1080/15440478.2012.738026.

(12) Saito, D.; Maeshima, Y.; Nasu, T.; Yamasaki, H.; Abe, K.; Sugiyama, H.; Sonoda, H.; Sato, Y.; Makino, H. Amelioration of Renal Alterations in Obese Type 2 Diabetic Mice by 
Vasohibin-1, a Negative Feedback Regulator of Angiogenesis. Am. J. Physiol. - Ren. Physiol. 2011, 300 (4), 873-886. https://doi.org/10.1152/ajprenal.00503.2010.

(13) Li, J.; Kang, M. K.; Kim, J. K.; Kim, J. L.; Kang, S. W.; Lim, S. S.; Kang, Y. H. Purple Corn Anthocyanins Retard Diabetes-Associated Glomerulosclerosis in Mesangial Cells and Db/Db Mice. Eur. J. Nutr. 2012, 51 (8), 961-973. https://doi.org/10.1007/s00394-011$0274-4$.

(14) Petroni, K.; Trinei, M.; Fornari, M.; Calvenzani, V.; Marinelli, A.; Micheli, L. A.; Pilu, R.; Matros, A.; Mock, H. P.; Tonelli, C.; Giorgio, M. Dietary Cyanidin 3-Glucoside from Purple Corn Ameliorates Doxorubicin-Induced Cardiotoxicity in Mice. Nutr. Metab. Cardiovasc. Dis. 2017, 27 (5), 462-469. https://doi.org/10.1016/j.numecd.2017.02.002.

(15) Long, N.; Suzuki, S.; Sato, S.; Naiki-Ito, A.; Sakatani, K.; Shirai, T.; Takahashi, S. Purple Corn Color Inhibition of Prostate Carcinogenesis by Targeting Cell Growth Pathways. Cancer Sci. 2013, 104 (3), 298-303. https://doi.org/10.1111/cas.12078.

(16) Lago, C.; Landoni, M.; Cassani, E.; Cantaluppi, E.; Doria, E.; Nielsen, E.; Giorgi, A.; Pilu, R. Study and Characterization of an Ancient European Flint White Maize Rich in Anthocyanins: Millo Corvo from Galicia. PLoS One 2015, 10 (5). https://doi.org/10.1371/journal.pone.0126521.

(17) Pilu, R.; Piazza, P.; Petroni, K.; Ronchi, A.; Martin, C.; Tonelli, C. Pl-Bol3, a Complex Allele of the Anthocyanin Regulatory P11 Locus That Arose in a Naturally Occurring Maize Population. Plant J. 2003, $36 \quad$ (4), 510-521. https://doi.org/10.1046/j.1365313X.2003.01898.x. 
(18) Lago, C.; Landoni, M.; Cassani, E.; Doria, E.; Nielsen, E.; Pilu, R. Study and Characterization of a Novel Functional Food: Purple Popcorn. Mol. Breed. 2013, 31 (3), 575-585. https://doi.org/10.1007/s11032-012-9816-6.

(19) Lago, C.; Landoni, M.; Cassani, E.; Atanassiu, S.; Canta-Luppi, E.; Pilu, R. Development and Characterization of a Coloured Sweet Corn Line as a New Functional Food. Maydica 2014, 59 (3), 191-200. https://doi.org/10.1371/journal.pone.0130110.

(20) Lago, C.; Cassani, E.; Zanzi, C.; Landoni, M.; Trovato, R.; Pilu, R. Development and Study of a Maize Cultivar Rich in Anthocyanins: Coloured Polenta, a New Functional Food. Plant Breed. 2014, 133 (2), 210-217. https://doi.org/10.1111/pbr.12153.

(21) Cassani, E.; Puglisi, D.; Cantaluppi, E.; Landoni, M.; Giupponi, L.; Giorgi, A.; Pilu, R. Genetic Studies Regarding the Control of Seed Pigmentation of an Ancient European Pointed Maize (Zea Mays L.) Rich in Phlobaphenes: The "Nero Spinoso" from the Camonica Valley. Genet. Resour. Crop Evol. 2017, 64 (4), 761-773. https://doi.org/10.1007/s10722-016-0399-7.

(22) Moreno, Y. S.; Sánchez, G. S.; Hernández, D. R.; Lobato, N. R. Characterization of Anthocyanin Extracts from Maize Kernels. J. Chromatogr. Sci. 2005, 43 (9), 483-487. https://doi.org/10.1093/chromsci/43.9.483.

(23) Cevallos-Casals, B. A.; Cisneros-Zevallos, L. Stability of Anthocyanin-Based Aqueous Extracts of Andean Purple Corn and Red-Fleshed Sweet Potato Compared to Synthetic and Natural Colorants. Food Chem. 2004, $86 \quad$ (1), 69-77. https://doi.org/10.1016/j.foodchem.2003.08.011. 
(24) Cuevas Montilla, E.; Hillebrand, S.; Antezana, A.; Winterhalter, P. Soluble and Bound Phenolic Compounds in Different Bolivian Purple Corn (Zea mays L.) Cultivars. J. Agric. Food Chem. 2011, 59 (13), 7068-7074. https://doi.org/10.1021/jf201061x.

(25) Žilić, S.; Serpen, A.; Akillioğlu, G.; Gökmen, V.; Vančetović, J. Phenolic Compounds, Carotenoids, Anthocyanins, and Antioxidant Capacity of Colored Maize (Zea mays L.) Kernels. J. Agric. Food Chem. 2012, 60 (5), 1224-1231. https://doi.org/10.1021/jf204367z.

(26) Paulsmeyer, M.; Chatham, L.; Becker, T.; West, M.; West, L.; Juvik, J. Survey of Anthocyanin Composition and Concentration in Diverse Maize Germplasms. J. Agric. Food Chem. 2017, 65 (21), 4341-4350. https://doi.org/10.1021/acs.jafc.7b00771.

(27) Zhao, X.; Zhang, L.; Liu, D. Biomass Recalcitrance. Part I: The Chemical Compositions and Physical Structures Affecting the Enzymatic Hydrolysis of Lignocellulose. Biofuels, Bioprod. Biorefining. 2012, 6, 465-482. https://doi.org/10.1002/bbb.1331.

(28) Lao, F.; Giusti, M. M. Extraction of Purple Corn (Zea Mays L.) Cob Pigments and Phenolic Compounds Using Food-Friendly Solvents. J. Cereal Sci. 2018, 80, 87-93. https://doi.org/10.1016/j.jcs.2018.01.001.

(29) Giusti, M. M.; Wrolstad, R. E. Characterization and Measurement of Anthocyanins by UVVisible Spectroscopy. In Current Protocols in Food Analytical Chemistry; John Wiley and Sons, $\quad$ Inc., $\quad$ H., $\quad$ Ed.; $\quad 2001 ; \quad$ p $\quad$ F1.2.1-F1.2.13. https://doi.org/10.1002/0471142913.faf0102s00.

(30) Wang, H.; Tang, Z.; Zhou, W. A Method for Dyeing Cotton Fabric with Anthocyanin Dyes Extracted from Mulberry (Morus rubra) Fruits. Color. Technol. 2016, 132 (3), 222-231. 
https://doi.org/10.1111/cote.12212.

(31) Jing, P.; Giusti, M. M. Effects of Extraction Conditions on Improving the Yield and Quality of an Anthocyanin-Rich Purple Corn (Zea mays L.) Color Extract. J. Food Sci. 2007, 72 (7), C363-C368. https://doi.org/10.1111/j.1750-3841.2007.00441.x.

(32) Abbasi-Parizad, P.; De Nisi, P.; Adani, F.; Sciarria, T. P.; Squillace, P.; Scarafoni, A.; Iametti, S.; Scaglia, B. Antioxidant and Anti-Inflammatory Activities of the Crude Extracts of Raw and Fermented Tomato Pomace and Their Correlations with Aglycate-Polyphenols. Antioxidants 2020, 9 (2). https://doi.org/10.3390/antiox9020179.

(33) Re, R.; Pellegrini, N.; Proteggente, A.; Pannala, A.; Yang, M.; Rice-Evans, C. Antioxidant Activity Applying an Improved ABTS Radical Cation Decolorization Assay. Free Radic. Biol. Med. 1999, 26 (9-10) 1231-1237. https://doi.org/10.1016/S0891-5849(98)00315-3.

(34) Goering, H. K.; Van Soest, P. J. Forage Fiber Analyses (Apparatus, Reagent, Procedures and Some Applications): Agriculture Handbook No. 379; 1970.

(35) Li, C. Y.; Kim, H. W.; Won, S. R.; Min, H. K.; Park, K. J.; Park, J. Y.; Ahn, M. S.; Rhee, H. I. Corn Husk as a Potential Source of Anthocyanins. J. Agric. Food Chem. 2008, 56 (23), 11413-11416. https://doi.org/10.1021/jf802201c.

(36) Kapcum, N.; Uriyapongson, J.; Alli, I.; Phimphilai, S. Anthocyanins, Phenolic Compounds and Antioxidant Activities in Colored Corn Cob and Colored Rice Bran. Int. Food Res. J. 2016, 23 (6), 2347-2356.

(37) Lao, F.; Giusti, M. M. Quantification of Purple Corn (Zea Mays L.) Anthocyanins Using 
Spectrophotometric and HPLC Approaches: Method Comparison and Correlation. Food Anal. Methods 2016, 9 (5), 1367-1380. https://doi.org/10.1007/s12161-015-0318-0.

(38) Escribano-Bailón, M. T.; Santos-Buelga, C.; Rivas-Gonzalo, J. C. Anthocyanins in Cereals. Journal of Chromatography A. 2004, pp 129-141. https://doi.org/10.1016/j.chroma.2004.08.152.

(39) De Pascual-Teresa, S.; Santos-Buelga, C.; Rivas-Gonzalo, J. C. LC-MS Analysis of Anthocyanins from Purple Corn Cob. J. Sci. Food Agric. 2002, 82 (9), 1003-1006. https://doi.org/10.1002/jsfa.1143.

(40) Lao, F.; Giusti, M. M. Extraction of Purple Corn (Zea Mays L.) Cob Pigments and Phenolic Compounds Using Food-Friendly Solvents. J. Cereal Sci. 2018, 80, 87-93. https://doi.org/10.1016/j.jcs.2018.01.001.

(41) Brouillard, R. Chemical Structure of Anthocyanins. In Anthocyanins As Food Colors; Elsevier, 1982; pp 1-40. https://doi.org/10.1016/b978-0-12-472550-8.50005-6.

(42) Yang, Z.; Han, Y.; Gu, Z.; Fan, G.; Chen, Z. Thermal Degradation Kinetics of Aqueous Anthocyanins and Visual Color of Purple Corn (Zea Mays L.) Cob. Innov. Food Sci. Emerg. Technol. 2008, 9 (3), 341-347. https://doi.org/10.1016/j.ifset.2007.09.001.

(43) Cavalcanti, R. N.; Santos, D. T.; Meireles, M. A. A. Non-Thermal Stabilization Mechanisms of Anthocyanins in Model and Food Systems-An Overview. Food Research International. 2011, 44, 499-509. https://doi.org/10.1016/j.foodres.2010.12.007.

(44) Steyn, W. J.; Wand, S. J. E.; Holcroft, D. M.; Jacobs, G. Anthocyanins in Vegetative 
Tissues: A Proposed Unified Function in Photoprotection. New Phytol. 2002, 155, 349-361. https://doi.org/10.1046/j.1469-8137.2002.00482.x.

(45) Tsuda, T.; Shiga, K.; Ohshima, K.; Kawakishi, S.; Osawa, T. Inhibition of Lipid Peroxidation and the Active Oxygen Radical Scavenging Effect of Anthocyanin Pigments Isolated from Phaseolus Vulgaris L. Biochem. Pharmacol. 1996, 52 (7), 1033-1039. https://doi.org/10.1016/0006-2952(96)00421-2.

(46) Wang, H.; Cao, G.; Prior, R. L. Oxygen Radical Absorbing Capacity of Anthocyanins. $J$. Agric. Food Chem. 1997, 45 (2), 304-309. https://doi.org/10.1021/jf960421t.

(47) Lopez-Martinez, L. X.; Oliart-Ros, R. M.; Valerio-Alfaro, G.; Lee, C. H.; Parkin, K. L.; Garcia, H. S. Antioxidant Activity, Phenolic Compounds and Anthocyanins Content of Eighteen Strains of Mexican Maize. LWT - Food Sci. Technol. 2009, 42 (6), 1187-1192. https://doi.org/10.1016/j.lwt.2008.10.010.

(48) Vankar, P. S.; Shukla, D. Natural Dyeing with Anthocyanins from Hibiscus rosa sinensis Flowers. J. Appl. Polym. Sci. 2011, 122 (5), 3361-3368. https://doi.org/10.1002/app.34415.

(49) McClure, J. W. Physiology and Functions of Flavonoids. In The Flavonoids; Springer US, 1975; pp 970-1055. https://doi.org/10.1007/978-1-4899-2909-9_18.

(50) Menter, J. M.; Hatch, K. L. Clothing as Solar Radiation Protection. Curr. Probl. Dermatol., 2003, 31, 50-63. https://doi.org/10.1159/000072237.

(51) Gies, P. H.; Roy, C. R.; Toomey, S.; McLennan, A. Protection against Solar Ultraviolet Radiation. In Mutation Research - Fundamental and Molecular Mechanisms of 
Mutagenesis; 1998; Vol. 422, pp 15-22. https://doi.org/10.1016/S0027-5107(98)00181-X.

(52) Gupta, D.; Jain, A.; Panwar, S. Anti-UV and Anti-Microbial Properties of Some Natural Dyes on Cotton. Indian J. Fibre Text. Res. 2005, 30 (2), 190-195.

(53) Grifoni, D.; Bacci, L.; Zipoli, G.; Albanese, L.; Sabatini, F. The Role of Natural Dyes in the UV Protection of Fabrics Made of Vegetable Fibres. Dye. Pigment. 2011, 91 (3), 279-285. https://doi.org/10.1016/j.dyepig.2011.04.006.

(54) Gawish SM, H. H. UV Protection Properties of Cotton, Wool, Silk and Nylon Fabrics Dyed with Red Onion Peel, Madder and Chamomile Extracts. J. Text. Sci. Eng. 2016, 6 (4). https://doi.org/10.4172/2165-8064.1000266.

(55) Zhang, Q.; Luna-Vital, D.; Gonzalez de Mejia, E. Anthocyanins from Colored Maize Ameliorated the Inflammatory Paracrine Interplay between Macrophages and Adipocytes through Regulation of NF-KB and JNK-Dependent MAPK Pathways. J. Funct. Foods 2019, 54, 175-186. https://doi.org/10.1016/j.jff.2019.01.016.

(56) Chen, L.; Teng, H.; Jia, Z.; Battino, M.; Miron, A.; Yu, Z.; Cao, H.; Xiao, J. Intracellular Signaling Pathways of Inflammation Modulated by Dietary Flavonoids: The Most Recent Evidence. Crit. Rev. Food Sci. Nutr. 2018, 58, 2908-2924. https://doi.org/10.1080/10408398.2017.1345853.

(57) Zhang, Q.; Gonzalez de Mejia, E.; Luna-Vital, D.; Tao, T.; Chandrasekaran, S.; Chatham, L.; Juvik, J.; Singh, V.; Kumar, D. Relationship of Phenolic Composition of Selected Purple Maize (Zea mays L.) Genotypes with Their Anti-Inflammatory, Anti-Adipogenic and Anti$\begin{array}{lllll}\text { Diabetic Potential. Food } & \text { Chem. 2019, 289, 739-750. }\end{array}$ 
https://doi.org/10.1016/j.foodchem.2019.03.116.

(58) Jung, H.; Kwak, H. K.; Hwang, K. T. Antioxidant and Anti-inflammatory Activities of Cyanidin-3-Glucoside and Cyanidin-3-Rutinoside in Hydrogen Peroxide and Lipopolysaccharide-Treated RAW264.7 Cells. Food Sci. Biotechnol. 2014, 23 (6), 20532062. https://doi.org/10.1007/s10068-014-0279-x.

(59) Zhao, X.; Zhang, C.; Guigas, C.; Ma, Y.; Corrales, M.; Tauscher, B.; Hu, X. Composition, Antimicrobial Activity, and Antiproliferative Capacity of Anthocyanin Extracts of Purple Corn (Zea mays L.) from China. Eur. Food Res. Technol. 2009, 228 (5), 759-765. https://doi.org/10.1007/s00217-008-0987-7.

(60) Prietto, L.; Pinto, V. Z.; El Halal, S. L. M.; de Morais, M. G.; Costa, J. A. V.; Lim, L. T.; Dias, A. R. G.; Zavareze, E. da R. Ultrafine Fibers of Zein and Anthocyanins as Natural PH Indicator. J. Sci. Food Agric. 2018, 98 (7), 2735-2741. https://doi.org/10.1002/jsfa.8769.

(61) Li, Y.; Ying, Y.; Zhou, Y.; Ge, Y.; Yuan, C.; Wu, C.; Hu, Y. A PH-Indicating Intelligent Packaging Composed of Chitosan-Purple Potato Extractions Strength by SurfaceDeacetylated Chitin Nanofibers. Int. J. Biol. Macromol. 2019, 127, 376-384. https://doi.org/10.1016/j.ijbiomac.2019.01.060. 


\section{For Table of Contents Use Only}

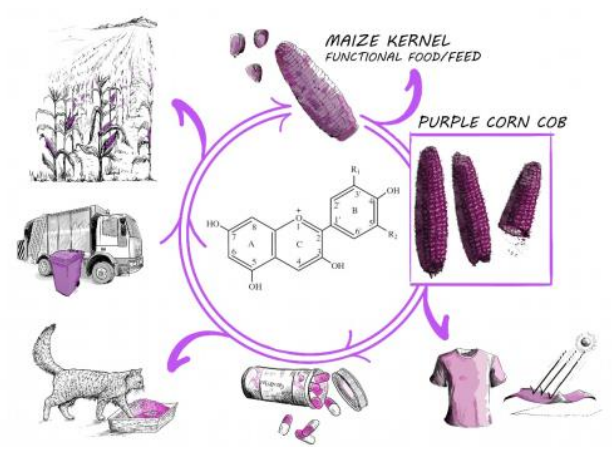

\section{Synopsis}

Cascade extraction approach allows makes purple corn cob recovery versatile and useful 